\title{
EDITORIAL
}

\section{Física Moderna e Contemporânea no Ensino Médio: Chamada de Artigos}

Há uma tentativa atual em muitos países e, em particular no Brasil, de inserir noções, conceitos, modelos e aplicações da Física Moderna e Contemporânea (FMC) nos cursos introdutórios de Física em todos os níveis de escolarização. No ensino médio, a Física é um bojo de conhecimentos que se acabou no final do século XIX. Quando muito, nossos estudantes aprendem a resolver problemas da Física Newtoniana. Se a escola for mais "exigente", possivelmente poderão aprender alguns grandes princípios da Física dos séculos XVIII e XIX.

Enquanto o Comitê Nobel resolveu premiar há dois anos as pesquisas em Física que foram fundamentais para a moderna Tecnologia da Informação, baseada na óptica-eletrônica, constituída de lasers, diodos, transistores, fibras ópticas e usadas em dispositivos modernos como celulares, CDs e satélites de comunicação, dentre outros, ensinamos, quando muito, a física dos pêndulos, da balística do século XVII, da termometria, das lentes etc.. Deixamos a Física mais excitante como aquela contida, por exemplo, no modelo padrão, na interação da radiação com a matéria, na cosmologia moderna, nos novos materiais fabricados pelo homem, para o pesquisador nas diversas instituições. Estes temas somente aparecem para o aluno em revistas de divulgação científica, em geral de pouca disponibilidade.

Diferentemente dos cursos de Astronomia em centros de ciências e observatórios que são atuais e conceituais (não envolvem álgebra), o nosso ensino de Física é bastante apoiado em tecnicalidades matemáticas, muito embora reconheçamos que a Matemática seja a linguagem da Física.

Na estruturação do novo ensino médio, a partir da promulgação da recente Lei das Diretrizes e Bases da Educação Brasileira (LDB), foram estabelecidos novos parâmetros que passam a regulamentar a definição geral dada na LDB. Em um contexto multidisciplinar as ciências exatas e a matemática aparecem juntas em uma das áreas com que o ensino está organizado. Segundo Menezes, coordenador da equipe que elaborou os novos parâmetros curriculares nacionais (PCN's): ${ }^{1} E$ parte desta preocupação (ressaltar o sentido da Física como visão de mundo, como cultura, em sua acepção mais ampla) a nova ênfase atribuída à cosmologia física, desde o universo mais próximo, como o sistema solar e em seguida nossa galáxia, até o debate dos modelos evolutivos das estrelas e do cosmos. Sabidamente, estão ausentes dos currículos tradicionais tanto estes aspectos de caráter cultural mais geral, como outros mais de cultura tecnológica, não necessariamente pragmática, a exemplo da interpretação de processos envolvendo transformações de energia, na geração de energia elétrica, nos motores de combustão interna, em refrigeradores, ou mesmo em pilhas eletroquímicas, para não falar nos equipamentos óptico-eletrônicos e de processamento de informação, que hoje fazem parte de toda a vida contemporânea, desde relógios de pulso a computadores, e que envolvem uma micro-eletrônica quântica, impensável na escola tradicional, nem mesmo como simples fenomenologia, especialmente devido à tradição lógico-dedutiva do seu ensino....É claro que precisa ser cautelosa a sinalização para a inclusão desses novos conteúdos, seja pelos desafios didáticos que implica, encontrando professores despreparados e os textos escolares desguarnecidos, seja porque as próprias universidades, ainda por algum tempo, continuarão a solicitar os velhos conteúdos em seus vestibulares. Será preciso algum tempo para que a mensagem seja, primeiro, compreendida e, mais tarde, aceita.

\footnotetext{
${ }^{1}$ MENESES, L.C., Uma Física para o Novo Ensino Médio. Física na Escola. v. 1, n.1, p.7, out. 2000.
} 
As justificativas sobre a inserção da FMC são muitas como aponta a pesquisa bibliográfica realizada por Ostermann e Moreira ${ }^{2}$. Destacamos algumas delas: estudantes precisam ter contacto com o excitante mundo da pesquisa atual em Física; os PCN's para o ensino médio apontam na direção de uma profunda reformulação do currículo de Física na escola média e a inserção da FMC nos currículos; uma maneira de atrair jovens para a carreira científica; disseminar os conhecimentos que a ciência a tecnologia propiciam à população; esclarecer o estudante quanto às pseudo-ciências. Os autores também concluem que as pesquisas desenvolvidas sobre FMC estão mais concentradas na "apresentação de um tema de FMC" em comparação com as pesquisas sobre "concepções alternativas" e "propostas testadas em sala de aula".

Há algum tempo, algumas publicações nacionais dirigidas para professores de física começam a refletir a preocupação acerca da inserção da FMC no ensino médio. Com a finalidade de contribuir neste esforço, a RBEF pretende lançar um número especial sobre o tema e convida todos os interessados, pesquisadores, professores do nível médio e superior, estudantes de pós-graduação a submeter artigos que visem: à análise e discussão de métodos para facilitar a aprendizagem dos tópicos de FMC; à identificação de dificuldades que possam impedir os estudantes de obter o mínimo de compreensão da FMC no ensino médio; ao desenvolvimento de material instrucional de FMC (textos didáticos, para-didáticos e de divulgação, pôsteres, páginas na internet, experimentos de baixo custo); e outros aspectos relevantes do tema. O prazo final para entrega dos artigos será anunciado oportunamente.

Um Feliz 2003 para todos os autores, pareceristas e leitores da RBEF.

${ }^{2}$ OSTERMANN, F.; MOREIRA, M. A. Uma revisão bibliográfica sobre a área de pesquisa "física moderna e contemporânea no ensino médio". Investigações em Ensino de Ciências, v. 5, n. 1, mar. 2001. 